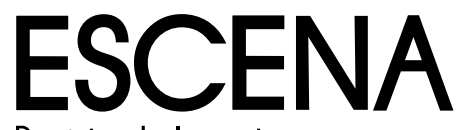

Revista de las artes
Publicación semestral. ISSN 2215-4906

Volumen 80 - Número 2

Enero - Junio 2021

\title{
Entre la crítica sociopolítica y la utopía artística: el Colectivo de Acciones de Arte (CADA), 1979-1985
}

Between Sociopolitical Criticism and Artistic Utopia: the Colectivo de Acciones de Arte (CADA), 1979-1985

Jorge Marchena Sanabria

\section{(c) (i) $($ 구 $€$}

Esta obra está bajo una licencia Creative Commons Reconocimiento-No comercial-Sin Obra Derivada 


\title{
Entre la crítica sociopolítica y la utopía artística: el Colectivo de Acciones de Arte (CADA), 1979-1985
}

\author{
Between Sociopolitical Criticism and Artistic Utopia: \\ the Colectivo de Acciones de Arte (CADA), 1979-1985
}

\author{
Jorge Marchena Sanabria ${ }^{1}$ \\ Universidad de Costa Rica \\ Costa Rica
}

Recibido: 29 de mayo de 2019

Aprobado: 20 de noviembre de 2019

\section{Resumen}

El presente ensayo tiene como fin elaborar un breve recorrido por las obras del Colectivo de Acciones de Arte (CADA), presentadas en Chile entre 1979 y 1985; momentos en que la dictadura de Augusto Pinochet se pretendía naturalizar. El CADA destaca, no solo como un ejemplo chileno de arte contemporáneo, sino por su oscilación entre una propuesta de vanguardia -acorde con las tendencias internacionales de la época- y la denuncia política. Precisamente, ante la represión y persecución del régimen y el apagón cultural que estaba experimentando el país, el Colectivo se enfocó en el rescate de la memoria y en la transmisión subrepticia de críticas y mensajes de resistencia. Por ello se analiza la visión que se ha construido en torno a este grupo, rozando con la idealización; proceso que no ha sido adrede. Para la elaboración de este trabajo, se retomaron diversas posturas teóricas en torno al arte contemporáneo, la revisión de artículos de revistas de la época, bibliografía y otros materiales que han sido preservados en torno a las obras que realizó el CADA.

Palabras clave: CADA; escena de avanzada; arte contemporáneo; Chile; memoria

1 Docente de la Universidad de Costa Rica en la Sede de Occidente y colaborador del Centro de Investigaciones en Identidad y Cultura Latinoamericanas (CIICLA). Máster en Historia Aplicada con énfasis en la Historia del Poder y Control Social por la Universidad Nacional. ORCID: 0000-00026928-4609. Correo electrónico: jorge.marchena@ucr.ac.cr 


\begin{abstract}
The purpose of this essay is to elaborate a brief tour through the works of the Colectivo de Acciones de Arte (CADA), presented in Chile between 1979 and 1985; moments in which the dictatorship of Augusto Pinochet was intended to naturalize. The CADA stands out, not only as a Chilean example of contemporary art, but also because of its oscillation between a vanguard proposal -corresponding to the international trends of the time-and political denunciation. Precisely, faced with the repression and persecution of the regime, as well as the "cultural blackout" that the country was experiencing, they led the Colectivo to focus both on the rescue of memory and on the surreptitious transmission of criticisms and messages of resistance. Another important aspect to analyze is the vision that has been built around this group, bordering on idealization; process that was not the result of mere chance. For the elaboration of this work, diverse theoretical postures around the contemporary art were taken up, as well as the review of articles of magazines of the time, bibliography, as well as other materials that have been preserved around the works that the CADA carried out.
\end{abstract}

Keywords: CADA; advanced scene; contemporary art; Chile; memory 
Entre la crítica sociopolítica y la utopía artística:

Dossier

el Colectivo de Acciones de Arte (CADA), 1979-1985

\section{Introducción ${ }^{2}$}

A finales del decenio de 1970, tras algunos de los peores episodios de la dictadura de Augusto Pinochet, la cual se extendió desde 1973 y hasta 1990, comenzaron las demostraciones públicas del Colectivo de Acciones de Arte o Grupo CADA: mantas cubriendo edificios públicos, poemas, hojas de papel en el aire, grafitis y otras pretendieron cuestionar al régimen autoritario. Sin lugar a dudas, su atrevimiento era grande, pues retaban de manera subrepticia, aunque pública, los pilares mismos del régimen. Uno de sus aspectos más llamativos, radicaba en la utilización del arte contemporáneo, como una herramienta idónea para la crítica sociopolítica y la preservación de la memoria histórica chilena. A partir de este arquetípico uso del arte para combatir un régimen no solo despótico, sino totalitario, se construyen diversas problematizaciones.

Para empezar, ¿qué representaba el Grupo CADA y, más importante, por qué tuvo éxito, especialmente, en momentos de extrema censura y persecución? Otro aspecto que se considera más que relevante y atinente a los temas de análisis del arte contemporáneo, se enmarca en ¿cómo fue superado el peligroso potencial de elitismo que pueden presentar las muestras artísticas de las últimas décadas? De esta forma, consideramos que CADA no representaban un mero ejercicio intelectual ni tampoco perseguía fines meramente comerciales, es decir, no buscaban fama o fortuna, sino que ambicionaron cambiar la realidad misma mediante una afrenta a la dictadura, además, ofrecieron una muestra de arte culto y popular.

El último punto que se pretende abordar radica en las razones o condiciones que permitieron que la propuesta de CADA fuera aceptada o, incluso, interiorizada o reapropiada por la sociedad civil chilena inmersa en la dictadura. Para ello, también se considera, como hipótesis que CADA no se limitó a un ejercicio de arte, sino que trascendió como una forma creativa de socavar a un régimen militar (se poría pensar que CADA creó un manual de cómo protestar en condiciones adversas y sobrevivir) y a la vez, se convirtió en un vehículo, voz sí se quiere, clandestina o subterránea de un Chile que no se dejó mancillar. CADA bien pudo representar a una sociedad silenciada, pero que no claudicaría y, mucho menos, olvidaría su pasado reciente.

2 Aprovecho para agradecer la lectura y propicias observaciones del Dr. Sergio Villena Fiengo sobre este trabajo y su iniciativa para publicarlo.

ESCENA . Revista de las artes, 2021, Vol. 80, Núm. 2 (enero-junio), pp. 127-151 
Por consiguiente, el artículo consta de varias secciones o ejes, aparte de la introducción y planteamientos teóricos en los que se trata de discutir el concepto de arte contemporáneo y crítica social que el CADA planteó, seguidamente se revisa brevemente el contexto chileno de la década de 1970 y comienzos de la de 1980 como parte indispensable para comprender el marco en que tuvieron lugar estas expresiones artísticas. De seguido, se ofrece un breve inventario de las obras del CADA, las cuales ya han sido ampliamente estudiadas -y con creces- por diversos autores (Katunaric, Neustadt y Richard por citar algunos). Luego, realizamos un balance del impacto y críticas en torno a la escena de avanzada y se incluyen las respectivas conclusiones, en las que se enfatiza los aportes sociales e históricos del CADA, pero eludiendo mistificaciones. Por último, las fuentes empleadas correspondieron a la documentación del CADA de acceso público y digital, así como diversos textos -libros y artículos- que se han escrito sobre esta temática.

\section{Observaciones teóricas}

En cuanto a los aspectos teóricos que guían este artículo ${ }^{3}$, se debe advertir que se considera que el arte, son aquellas obras humanas - de diversa índole y formato- que despiertan las emociones humanas: fascinación, conmoción, seducción, placer, tristeza y que son representaciones, tanto del mundo natural, como del humano, incluyendo lo abstracto y conceptual. Además, no se debe confundir arte como mera belleza o crecimiento espiritual y tampoco dependen estrictamente de la técnica con que se elaboró (Danto, 1997, p. 38). Por ende, las obras del CADA aparte de su carácter un tanto intempestivo, corresponden propiamente al arte contemporáneo, incluso al extremo, ya que rebozaban o estaban anclados a su momento histórico, al presente que había establecido la dictadura. Igualmente, otra definición, partiendo de las tesis de Agamben (2011), el cual se mostraba menos optimista hacia esta contemporaneidad artística, señalaría que el Colectivo se había esmerado en plantear una forma de arte muy vinculada con las modas estéticas de la segunda mitad del siglo XX.

En otra vertiente interpretativa, un tanto complementaria, se puede considerar que el CADA tenía como objetivo ser novedoso y alejarse de los esquemas convencionales -sobre

3 Cabe aclarar que se retoman parcialmente autores y corrientes de distintas procedencias, el artículo no se adscribe a un marco teórico de forma monolítica; el objetivo no es encadenarse ni adoptar a priori ninguno de ellos, sino, trazar una guía o contar con pautas que permitan explicar al CADA. 
Entre la crítica sociopolítica y la utopía artística:

Dossier

el Colectivo de Acciones de Arte (CADA), 1979-1985

todo del arte culto que homologaban con Pinochet y sus partidarios-, al contrario, la propuesta giraba en torno a la trasgresión, lo híbrido, incluso, lo difuso como ha sido definido en términos generales para el arte contemporáneo por Jiménez (2010). De esta forma, las viejas estéticas de las élites eran rechazadas (las bellas artes, el museo convencional...) y se pretendía alcanzar al público (no confundido con vulgo) de una forma un tanto utópica: llegar al corazón e intelecto de la ciudadanía chilena.

A diferencia de formas de arte más tradicionales, el CADA no solía emplear como espacios expositivos galerías o museos para transmitir su mensaje, por lo que optó por lugares públicos. De ahí que muchas de sus muestras, fueran cercanas al performance y la cotidianeidad, como más adelante se precisará ${ }^{4}$. No obstante, gran parte de las piezas exhibidas eran simples objetos cotidianos: mantas, bolsas de leche, muros, hojas de papel, ropa... que la mano del artista transfiguraba en obras, pero eso lleva al problema de la definición de arte, ¿era cualquier cosa? ¿Perdía su aura? (Jiménez, 2010). Bajo la postura anterior, los objetos cotidianos del CADA no poseían aura. Más bien, la clave o el problema de fondo nos parece que radicaba en los límites entre el arte contemporáneo y la crítica social, una que pretendía ser desgarradora o como procuraba el CADA, despertar consciencias. Por eso, y retomando al filósofo Marc Jiménez (2010), se puede dejar asentado que coincidimos en una definición de arte contemporáneo como uno comprometido con el cuestionamiento profundo de la realidad y del statu quo; a la vez, es críptico, no diáfano, porque confía en la capacidad de reflexión e introspección de cada persona, sin importar su nivel socioeconómico.

El CADA defendió la postura de que todos los seres humanos eran artistas en potencia, aunque ello no excluye que mostraran cierto elitismo cultural o que rozaran con un pretensioso complejo de superioridad moral e intelectual (cierta noción de vanguardia que defendieron y que se comentará en las siguientes páginas). Aquí, cabe anotar una peculiar diferencia con respecto a otros artistas comerciales y es que, a pesar de las críticas que se han esgrimido contra algunas vertientes del arte contemporáneo, especialmente, por la

${ }^{4}$ En este artículo se entiende performance como ejecución y puesta en escena, para el caso del CADA, también como arte callejero, en vivo y disruptivo (Taylor y Fuentes, 2011, pp. 8-11). Por otra parte, algunas acciones del Colectivo se acercaban al happening, ya que requerían de la participación de los espectadores, convertidos en artistas. Otras, eran más próximas al performance, puesto que el factor de improvisación podía ser muy alto, incluso, salirse de control. En algunos momentos, el CADA oscilaba entre uno y otro.

ESCENA . Revista de las artes, 2021, Vol. 80, Núm. 2 (enero-junio), pp. 127-151 
especulación y sometimiento al mercado neoliberal, es decir, obras en extremo comercial, así como pretendidas obras que no son más que modas y mensajes vacuos. Este colectivo chileno eludió la mercantilización artística y hasta cierto punto, optó por una propuesta legítima, consciente y coherente. Su obra podía ser efímera, pero el propósito era realizar, aunque fuera una pequeña ruptura en el edificio monolítico del régimen dictatorial.

También, se debe tener presente que el arte, a lo largo de la historia y no solo partiendo de la óptica eurocentrista, ha tendido a la magnificación de los grupos de poder (para muestra, la multitud de retratos y esculturas de reyes o grandes hombres), así como el tema del coleccionismo de arte. Especialmente, en las últimas décadas, con la explosión de la especulación y la conversión de obras en meras mercancías, sin valor cultural. Entonces, se podría afirmar que el arte, tradicionalmente, se ha comprometido con representar a las élites, sus prácticas y, a la vez, se han convertido en parte de su propia parafernalia. Lo anteior ya que las obras de arte bajo esta perspectiva en particular, encarnan el buen gusto y son parte del habitus de las clases altas, sus productos preferidos ${ }^{5}$. Esto se vuelve central para el CADA, ya que el arte no debía -sobre todo en las sociedades democráticas-adular o hacer deferencia a las élites o, en este caso específico, a los sistemas dictatoriales.

El párrafo anterior obliga a traer a colación una condicionante geopolítica vital para el caso latinoamericano. Aparte del factor poder en el arte, en general, también persiste un fuerte eurocentrismo, sobre todo el culto a las bellas artes; lo cual se ha traducido en el apoyo -público y privado- de iniciativas enfocadas en la pintura y la escultura, en menoscabo de otras expresiones. A ello se suma, otra serie de falencias, tales como la imposición de valores neoliberales en las artes, la excesiva mercantilización, acompañada de la especulación voraz (que mira solo hacia el coleccionismo), la falta de financiamiento de proyectos independientes y un largo etcétera ${ }^{6}$. Como si esto no fuera poco, un viejo lastre que ha

${ }^{5}$ Siempre con Bourdieu como telón de fondo, cabe preguntarse, ¿qué son las bellas artes?, ¿quiénes deciden lo que debe ser estético y admirable? Es un mundo que se auto-legitima, adicto a la adulación, cuando en la práctica, mercantiliza la cultura, a la vez, que excluye a formas que considera nocivas, vulgares, populares... Por ello, el sociólogo francés insiste en que las artes se han empleado para justificar la hegemonía, para crear diferenciaciones y, de ahí, el peligro de instituciones como la escuela y el museo que todavía las quieren perpetuar (Bourdieu, 2010).

${ }^{6}$ Otro problema anexo es la insistencia de muchos artistas en convertirse -lo antes posible- en celebridades y súper estrellas, por lo que su compromiso real está claramente vinculado con el mercado y en la obtención de dinero y prestigio; reforzando la concepción de un arte como sinónimo

ESCENA . Revista de las artes, 2021, Vol. 80, Núm. 2 (enero-junio), pp.127-151 
Entre la crítica sociopolítica y la utopía artística:

Dossier

el Colectivo de Acciones de Arte (CADA), 1979-1985

perseguido a todas las formas artísticas, se encuentra en la profunda desconexión entre los pretendidos artistas y la realidad latinoamericana (Acha, 1994, p. 176); un arte-moda, globalizado, pero al final de cuentas, vacío y desprovisto de un ápice de criticidad o de compromiso con la historia y los sufrimientos de la región?

\section{El contexto chileno: el asedio de la dictadura totalitaria-estética}

A inicios de la década de 1970, Chile se logró proyectar como la democracia más avanzada de Latinoamérica, libre de golpes de Estado y con un sistema electoral límpido y que permitiría (en teoría) la rotación de partidos; incluyendo los socialistas y comunistas. Con el triunfo de la Unidad Popular y su candidato, Salvador Allende, por primera vez ascendía al poder, por la vía de las urnas, una organización de clara extracción marxista. El optimismo fue elevado y las celebraciones de la izquierda internacional no se hicieron esperar.

A pesar de sus claras tendencias socialistas, el régimen de Allende se mostró hasta cierto punto, moderado. Pretendía reducir las desigualdades en el campo, sobre todo, enfocado en el problema del latifundismo y, además, ofrecía elevar la inversión en los sectores marginales, el aumento en salarios y otras garantías sociales. No obstante, las baterías del gobierno pronto se enfilaron en la consecución de la nacionalización del cobre, producto estrella de las exportaciones chilenas. Aparte de la conocida férrea oposición del binomio Nixon-Kissinger, las élites locales se mostraron recalcitrantes y comenzaron a boicotear activamente la administración Allende; el descontento de ciertos sectores -matizado por la élite y la derecha extrema- logró el desprestigio del presidente y lo ubicó en una posición endeble, tanto para gran parte de la ciudadanía, como para la opinión pública internacional (Bruna, 1976, pp. 120-134).

Cabe reiterar que las medidas de Allende no eran radicales en el sentido estricto de la palabra, además, el gobierno insistía en utilizar vías legales y apegadas a la constitución,

de mera decoración y caprichos de ricos (García Canclini, 2010, pp. 212-214). Hasta donde se ha podido analizar, el CADA nunca persiguió el estrellato y, aunque algunos de sus miembros se consagraron como figuras de peso en el arte chileno, no se les podría declarar a priori como artistas comerciales y pueriles.

7 Aunque esto no niega la existencia de artistas, expresiones y críticas socialmente comprometidas. No obstante, coincidimos con García Canclini (2010) y Acha (1994) en cuanto a las limitaciones antes señaladas.

ESCENA . Revista de las artes, 2021, Vol. 80, Núm. 2 (enero-junio), pp. 127-151 
pero a pesar de las apariencias, la democracia chilena no era tan tolerante como pretendía. Para empezar, la tradición política del país sureño se ubicaba hacia la derecha, por lo común, los comicios se jugaban entre organizaciones relativamente afines, ajenas a la izquierda. A esto se debe sumar que el bloque dominante chileno, simplemente, no toleró más y tomó la decisión de anular la democracia y entronar una dictadura violenta, carente de impedimentos morales. Aquel fatídico 11 de setiembre de 1973, tras semanas de meticulosa preparación y con el cruento bombardeo del Palacio de la Moneda, sede del ejecutivo, Augusto Pinochet ascendió al poder, representando a las fuerzas militares de línea dura y a las élites que no le darían cuartel al socialismo; una vez más, se reproducían los horrores de la Guerra Fría en Latinoamérica.

Harto conocido, la dictadura de Pinochet no solo brilló por la aplicación -la primera de hecho- del paquete neoliberal, ya que se empeñó en reducir al Estado chileno a una mera figura gendarme, el ensayo luego sería replicado en otras regiones del globo. Privatizaciones, reducción del ahora denominado gasto público y, sobre todo, la entronización del culto al libre mercado, reemplazaron las políticas de la Unidad Popular. Pero, también destacó por el uso desenfrenado del terror estatal: campos de tortura, encarcelamiento, desaparecimientos, escuadrones de la muerte, uso indiscriminado de la violencia, entre otros (Hinkelammert, 2012, pp. 46-50). A esto se suma, en correlación directa con el tema a desarrollar, que las principales universidades fueron casi desmanteladas por completo y gran parte de los departamentos de Humanidades, Artes y Filosofía condenados a una relativa extinción.

La dictadura no se contentó con la horripilante persecución y represión desencadenadas. Pronto, para asegurar su propio sostenimiento y partiendo de tendencias claramente totalitarias -control corporal y de la psique-, optó por un fuerte contraataque en el campo artístico-cultural. Las medidas rozan con lo absurdo, ya que se optó por borrar cualquier rastro del periodo de la Unidad Popular (UP): Ios colores del partido fueron prohibidos, la

8 Es importante destacar que el neoliberalismo chileno, guiado casi directamente por Milton Friedman y los denominados Chicago boys [Escuela de Economía de la Universidad de Chicago] tendría un cierto éxito inicial, desmedidamente publicitado por la dictadura. Los logros, enfocados en la reducción del aparato estatal, no fueron tan exitosos como se planteó. A inicios de la década de 1980, el régimen tuvo que dar marcha atrás, despedir a una parte significativa de sus asesores económicos y comenzó la aplicación de solapadas medidas intervencionistas, no solo había que atajar el crecimiento de la pobreza y la miseria, también había que apuntalar al sector privado. En otras palabras, la farsa neoliberal no tuvo los éxitos esperados (Collier y Sater, 1999, pp. 315-317).

ESCENA . Revista de las artes, 2021, Vol. 80, Núm. 2 (enero-junio), pp.127-151 
Entre la crítica sociopolítica y la utopía artística:

Dossier

el Colectivo de Acciones de Arte (CADA), 1979-1985

figura de Allende o el Che Guevara también fueron borradas. Asimismo, la música de protesta fue censurada, incluyendo expresiones anglosajonas que fueron acusadas de pervertir a la juventud chilena. El cabello largo en varones, ciertas apariencias entre las mujeres, todas fueron objeto de estricto escrutinio y sanción (Errazuriz, 2009, p. 145). El objetivo del nuevo orden tenía dos aristas, borrar la memoria histórica y física del pasado marxista, la otra, encumbrar el culto en torno a los militares.

De esta forma, se promovió el regular juramento a la bandera, los monumentos a los supuestos mártires de las fuerzas armadas y otros símbolos castrenses. Además, se realizaron sendos esfuerzos en defender la verdadera chilenidad, un nuevo movimiento de nacionalismo extremo. Esto se vio acompañado por la promoción de las artes oficiales, paralelo al exilio de artistas que se atrevieran a recordar el pasado o cuestionar a Pinochet, por ejemplo, canciones que rescataran el folclor chileno, por eso, en el tema musical, la siguiente cita es reveladora:

Esta cruzada por la chilenidad tuvo en la música folclórica "auténticamente chilena", vale decir, en la "música sin contenido político" y particularmente en el conjunto "Los Huasos Quincheros" una de sus máximas formas de expresión. Estos "huasos", que respaldaron decididamente el golpe militar, se transformaron en embajadores a nivel internacional de lo que pasó a denominarse como el "verdadero folclore chileno" y apoyaron activamente a las nuevas autoridades, no solo en eventos musicales sino también en la promoción de iniciativas tendientes a rescatar la chilenidad. Tal es el caso, por ejemplo, del concurso Nuevas Canciones para Los Quincheros, el que, con el apoyo de la Secretaria General de Gobierno, tuvo por objetivo ampliar su repertorio con música tradicional chilena, esto es, aquella "que le canta a las cosas simples, al paisaje, al romanticismo y que toma el ritmo de tonadas y cuecas (Errazuriz, 2009, p. 149).

También, se sumó una historiografía que glorificara y justificara, los horrores del golpe de Estado. Otra de sus medidas más excéntricas, digna de mención, radicó en el intento por rescatar un paisaje prístino de la ruralidad chilena, esto dio paso a la restauración de casas de campo. En el trasfondo, se estaba exaltando el latifundismo que había pretendido combatir el gobierno de Allende; precisamente, el paisajismo fue una de las expresiones artísticas más en boga durante estos años, practicada por los defensores del régimen, así como por sus detractores. Por ende, en este convulso e inseguro contexto, cualquier expresión artística alternativa y crítica recibiría no solo trabas, sino que podría enfrentarse

ESCENA . Revista de las artes, 2021, Vol. 80, Núm. 2 (enero-junio), pp. 127-151 
a la furia de la dictadura. En estos momentos de alta tensión, cuando el régimen pretendía naturalizarse, es que comienza a surgir el disidente proyecto del grupo CADA.

\section{La propuesta ¿vanguardista? del CADA}

El Grupo CADA inició sus actividades en la ciudad de Santiago, durante el año de 1979. Se podría afirmar, que sus acciones se inscribían más en la esfera política que en la artística, ya que su objetivo explícito era utilizar el poder cultural de las artes para recuperar la dignidad nacional en tiempos de profundas tribulaciones: el empleo de la cultura como defensa contra la fuerza bruta de la dictadura ${ }^{9}$. En ese momento histórico, el arte no tenía autonomía, pero a la vez, le prestó muletas a la política o más importante, le ofreció metáforas y formas de renovación (Neustadt, 2013, p. 106).

Sus miembros consistieron en los artistas visuales Lotty Rosenfeld y Juan Castillo, la escritora Diamela Eltit, el poeta Raúl Zurita y el sociólogo Fernando Balcells ${ }^{10}$. La máxima

9 Por razones de espacio y para evitar una mayor desviación del tema central, se omitió un nivel macro de contextualización, referido sobre todo al caso latinoamericano. Con suma brevedad, se puede apuntar que gran parte de la región también fue asediada por dictaduras, muchas con un signo neoliberal como el chileno, pero otras con fuertes inclinaciones comunistas. Este auge autoritario bien se extendió desde principios de la década de 1970 y hasta el primer quinquenio de la de 1990 (Lucena y otros, 2008), cuando, supuestamente, triunfan los procesos democratizadores. No obstante, la perduración de pandillas (o maras) para el caso centroamericano, carteles de drogas (México y Colombia), el terrorismo de Estado o, en general, violencia y corrupción, han sido permanentes en toda esta zona hasta el presente. Todos estos procesos han influido en que las artes se convirtieran en una herramienta para la crítica o como una válvula de escape ante el dolor, de ahí que su uso con fines políticos bien antecedió al CADA. Los casos son múltiples, con éxito variado y algunos cuestionados por ligeros, poco profundos o más interesados en el espectáculo. Como ejemplos, se puede citar a Teresa Margolles (México), Regina Galindo (Guatemala), Raúl Quintanilla (Nicaragua), Tania Bruguera (Cuba), entre otros. Asimismo, Camnitzer considera que el artista latinoamericano, de forma un tanto esquemática, corresponde u oscila entre un agitador (político) y constructor de cultura, inclusive, como una utópica (2009, p. 33); sobre todo en el campo del arte conceptual.

${ }^{10}$ Comúnmente, se ha asegurado que la base intelectual del grupo se encontraba en Zurita, a esto se debe sumar, que tanto él como Eltit, realizaron obras literarias y de crítica, paralelas al CADA, de ellas destaca Purgatorio de Zurita publicada en 1979 y Lumpérica (1983) de Eltit. Ambas, eran muestras rebosantes de subjetividad, acerca de la agonía y el dolor que experimentaron en aquellos años. Por otra parte, una descripción detallada de los miembros, sus obras y trayectoria general, se pueden encontrar en las obras consultadas y explicitadas en las referencias; sobre todo en Soto (2016).

ESCENA . Revista de las artes, 2021, Vol. 80, Núm. 2 (enero-junio), pp.127-151 
Entre la crítica sociopolítica y la utopía artística:

Dossier

el Colectivo de Acciones de Arte (CADA), 1979-1985

del Colectivo se podría sintetizar como la conducción a un "complejo pensar, al bastardaje barrial de una áspera comuna" (Neustadt, 2013, p. 34); dicho en otras palabras, una fusión entre arte culto y popular.

Asimismo, CADA se declaraba como fiel representante local de la escena de avanzada, una suerte de arte contemporáneo, pero supuestamente desligado de modas y de los principales circuitos internacionales y que correspondía, sobre todo, a una vanguardia artística contra la dictadura (Soto, 2016, p. 219). Esto también se debía a que, en un entorno de retorno al conservadurismo cultural, el Colectivo empleaba medios alternativos, el uso de la televisión, el teatro, la plástica, música y, en general, la experimentación como eje central. En consecuencia, serían considerados como jóvenes impetuosos (o locos) por la derecha gobernante y de elitistas, por la izquierda perseguida (Katunaric, 2008, p. 300). Pero no eran elitistas, no era tan simple como el binomio anterior de conservadores versus progresistas, CADA se enmarcaba también en el proceso de nacimiento de la nueva izquierda latinoamericana (abandonando las representaciones ideológicas totalizantes de la izquierda tradicional), la cual se desprendía de la revolución como su máximo ideal y sobre todo, en el contexto del predominio del autoritarismo en Chile y Latinoamérica, por extensión, se avocaron por defender una transición pronta y segura hacia la democratización (Richard, 1991, pp. 109-110) ${ }^{11}$.

De igual modo, la avanzada consistió en un intento de simbiosis entre arte/sociedad/política y se caracterizó por su nivel de ambigüedad, ya que sus puestas en escena se alejaban del arte tradicional, recurriendo en cambio, a los simbolismos y al rescate de la memoria en torno a la presidencia de Allende; pequeñas muestras u objetos que apelaban a una ciudadanía silenciada. Ahora, en la práctica y como lo expuso Camnitzer, la principal prioridad de gran parte de los artistas durante la dictadura de Pinochet, incluyendo al CADA, consistió en construir propuestas que no despertaran la ira del régimen, máxime cuando era impredecible en cuanto a sus preferencias artísticas se refiere, puesto que se mostraba ignorante y trivial o también, siguiendo a la oligarquía, pretendía ser cosmopolita y refinado

\footnotetext{
${ }^{11}$ Lechner también compartía esta postura y cuestionaba los mitos de la izquierda, enfatizando en que se requería de una nueva cultura política creativa y no determinista, ajena a "visiones omnicomprensivas de la realidad" (1987, p. 254), así como la necesidad de desprenderse de visiones sectarias (mesiánicas) y en exceso utopistas. Por el contrario, el autor llamaba la atención sobre la necesidad de realismo político y suprimir la dramatización del campo político y, en consonancia, con lo desarrollado por CADA, a revalorar lo callejero o, más importante, lo cotidiano.
}

ESCENA . Revista de las artes, 2021, Vol. 80, Núm. 2 (enero-junio), pp. 127-151 
(2009, p. 115). Por ello, la solución consistió en publicitarse como artistas afines a las modas internacionales y se prefería el elitismo, ya que sí las masas no comprendían el mensaje, ¡el dictador estaba complacido!

Entonces, la propuesta del CADA no se puede reducir a mera variante del vanguardismo, ya que podía servir como una estrategia de supervivencia y evasión con respecto a la censura y represión oficial. De esta forma, su propuesta consistió en acciones de arte o performances que requerían de una estrecha participación-complicidad de los transeúntes para transmitir mensajes o discusiones políticas vedadas, así como el compromiso con un arte público y callejero. Para el grueso de autores empleados en este escrito, CADA es un idealizado sinónimo de resistencia, dado que su arte no estaba encerrado en museos, sino que le pertenecía a la sociedad o de forma más concreta, era un arte explícitamente político y comprometido (Katunaric, 2008, p. 299).

Por ende, las acciones rivalizaron no solo con la censura dominante, sino con los rituales del arte elitista y privado, así como institucional, que gozaban del beneplácito del Régimen. Esta disidencia artística conllevaría a que el CADA asumiera un proyecto que se declaraba como inclusivo: callejero, serial (objetos cotidianos) y dirigido a la persona común. En contraste con la exclusividad del arte oficial: enclaustrado en el museo, que giraba en torno al objeto único y dirigido a un espectador burgués culto e iniciado en los saberes de las bellas artes. Mientras la dictadura había promovido una cultura oficial propia del binomio victimario-dictadura, en el polo opuesto se ofrecían alternativas como la escena de avanzada: cultura popular-victimado-sociedad civil.

A esto se debe agregar que, dado el clima represivo y los citados objetivos del arte didáctico-popular, el Colectivo emplearía espacios sociales y no textuales, ello exigía que sus obras fueran efímeras, ya que se recordaban trazos de aquello que se estaba negando y, a la vez, se sorteaba la persecución. Es importante insistir que el objetivo era lograr que los espectadores-participantes pensaran o, por lo menos, recordaran el pasado con Allende; de allí se reforzaba la ambigüedad antes citada, el mensaje no podía ser lineal, unívoco ni mucho menos, autoritario, suscitaba preguntas y abría la posibilidad de entablar diálogos, aunque fuera al interior de cada persona (Neustadt, 2013, pp. 30 y 38). 
Entre la crítica sociopolítica y la utopía artística:

Dossier

el Colectivo de Acciones de Arte (CADA), 1979-1985

\section{Un breve inventario de las principales obras del CADA}

Dado que una multitud de trabajos y ensayos han revisado la obra del Colectivo, en este apartado solo se hará referencia a una breve descripción de las propuestas que realizaron entre 1979 y 1984, momento en que el grupo se disolvió o, que sus actividades públicas cesaron ${ }^{12}$. La primera puesta en escena consistió en el conjunto denominado Para no morir de hambre en el arte, realizado el 3 de octubre de 1979. Se dividió en tres partes: en la primera se obsequiaron cien bolsas de medio litro de leche en la comuna La Granja, ubicada al sur de Santiago. El objetivo era recordar el programa de alimentación para todos los infantes chilenos, que había promovido Salvador Allende pocos años atrás. Además, el Colectivo buscaba rescatar zonas marginales que la dictadura y sus políticas de embellecimiento e higienismo social estaban dejando de lado, aunque ello pudiera implicar la idealización de estos mismos espacios (Macchiavello, 2014, p. 103). Por otra parte, las bolsas fueron recuperadas y entregadas a otros artistas para que las personalizaran y ampliaran el espectro creativo-crítico.

La segunda fase, como se le podría denominar, correspondió a la publicación de una página en blanco en la revista Hoy, con el objetivo de recordar los vacíos y ausencias que asolaban a la sociedad chilena, dado que no se pudo imprimir una hoja carente de texto (aunque era común la censura en torno a fotografías), el Colectivo agregó las siguientes líneas:

Imaginar esta página completamente blanca.

Imaginar está página blanca

accediendo a todos los rincones de Chile

como la leche diaria a consumir.

Imaginar cada rincón de Chile

privado del consumo diario de leche

como páginas blancas por llenar

(CADA, octubre de 1979)

${ }^{12}$ En varios sitios de internet se encuentran fotografías, videos y otros vestigios del CADA. Revisar, por ejemplo, Zurita (s.f.).

ESCENA . Revista de las artes, 2021, Vol. 80, Núm. 2 (enero-junio), pp. 127-151 
La última fase de esta acción consistió en la lectura del manifiesto "No es una aldea" frente a las oficinas chilenas de la Comisión Económica para América Latina y el Caribe de las Naciones Unidas (CEPAL), el organismo que desde mediados del siglo XX había venido insistiendo en la necesidad de un desarrollo hacia el interior de la región y en frenar la dependencia con respecto a los países del primer mundo. En este documento, básicamente se hacía referencia a la tiranía que asolaba a casi todo el planeta y se recordaba cómo se había dado la espalda a las tesis cepalinas, encumbrado el neoliberalismo y el culto al libre mercado.

La siguiente acción correspondió a la picaresca Inversión de escena que tuvo lugar el 17 de octubre del mismo año. Esta consistió en un desfile de camiones de leche de la marca SOPROLE y en el encubrimiento de la fachada del Museo de Bellas Artes, situado en la capital. El CADA, en una muestra de audacia, convenció a las autoridades de la institución que se trataba de una inocente conmemoración del centenario del museo (Richard, 2004). Además, aprovecharon la convalecencia de la directora de este, para su realización. La manta representaba el bombardeo sobre el Palacio de la Moneda, aquel tétrico 11 de setiembre de 1973, y los camiones lecheros hacían eco del desfile de tanquetas que ese mismo día había asolado a la incauta ciudad y al mártir de Allende. Otro de los propósitos, era demostrar que, en el exterior, también había cultura; más allá de la pretensión de un Museo servil hacia la dictadura (Neustadt, 2013, p. 32) ${ }^{13}$.

Por razones desconocidas, el CADA se mantuvo relativamente inactivo por los siguientes meses. No es difícil deducir que el clima de represión, la falta de recursos para el arte independiente, así como cierto nivel de vigilancia o descontento que provocaron sus anteriores acciones los obligaron a un cierto repliegue o a la espera de un mejor momento para reiniciar sus cuestionamientos. En junio de 1981, regresaron con la propuesta de ¡Ay Sudamérica!, que consistió en el empleo de una pequeña columna de aviones de las Fuerzas Aéreas y el metafórico bombardeo con poesía -cuatrocientos mil volantes- sobre la ciudad de Santiago. Para lograr la respectiva autorización, el Colectivo aseguró que se trataba de un proyecto de arte que emulaba a las grandes corrientes internacionales, sobre todo, de Estados Unidos y Europa occidental. Las respectivas autoridades, temiendo

${ }^{13}$ Eltit advertía que este tipo de trabajos demandaban de sumo cuidado, ya que las calles eran lugares "sucios" y "contaminados de ciudadanía", el proceso creativo se podía tornar incontrolable y estaba el riesgo de que las respuestas del público no fueran las esperadas o, en el peor de los casos, ninguna (Neustadt, 2013, p. 37).

ESCENA . Revista de las artes, 2021, Vol. 80, Núm. 2 (enero-junio), pp.127-151 
Entre la crítica sociopolítica y la utopía artística:

Dossier

el Colectivo de Acciones de Arte (CADA), 1979-1985

la vergüenza de quedar excluidos, accedieron a colaborar (Foxley, 1981, p. 46). El poema, en esencia, exaltaba de forma utópica las capacidades artísticas de todos los seres humanos, haciendo hincapié en que cualquier persona que busca la concreción de un mundo mejor y ampliar su mente, ya era un artista. De paso, volvían a rechazar el arte tradicional y de élite; aunque la acción, sobre todo con el despliegue de los aviones, motivó cierto rechazo entre la ciudadanía, ya que una formación aérea despertaba malos recuerdos y provocaba cierto temor (Sánchez, 2014, p. 28-29).

Las otras metáforas que se pretendieron aludir, hacían referencia, nuevamente, al bombardeo de 1973 sobre la casa presidencial, La Moneda, así como insistieron en que la dictadura no podía tomar los cielos y que, más bien, desde allí, se podían crear paisajes libres de prohibiciones. Estos poemas del CADA eran pequeños fragmentos o trozos de papel que buscaban crear fugas dentro de la cotidianeidad y la historia oficial impuesta ${ }^{14}$. Años más tarde y visto en retrospectiva, la hoy reconocida escritora Damiela Eltit, comentaba que al final de cuentas, era una metáfora débil, pero la única a la que pudieron recurrir en ese momento. Ahora, cabe señalar que, para el momento en que se realizó esta toma figurada, la resistencia se había recrudecido, paralelamente, la dictadura comenzaba a presentar severas grietas, pues su programa económico no había surtido los efectos deseados y la crisis mundial también tocaba a su puerta. En ese momento en particular, habían aumentado las concentraciones de ciudadanos descontentos, se intensificó la lucha por los derechos humanos y las actividades de otros colectivos de arte.

En abril de 1983, CADA realizó una nueva obra, titulada Residuos americanos, la cual no suele estar incluida en las referencias sobre el Colectivo, puesto que difiere parcialmente de sus muestras anteriores e, incluso, de las subsiguientes. Esta obra consistió en una exhibición de ropa usada en Washington D.C. El tema trataba acerca de las sobras del consumismo, reempaquetadas hacia el tercer mundo que, en realidad, estaban gastadas y eran casi desechos. Consistía en una crítica no solo al sistema capitalista, sino a la participación de Estados Unidos en la entronización de Pinochet, puesto que Chile -y Latinoaméricadebían lidiar con la basura y la suciedad que las mismas potencias creaban. No obstante, a

${ }^{14}$ El historiador del arte, Ernesto Calvo, también ha sugerido que este bombardeo pudo haber sido una rememoración de los denominados vuelos de la muerte que practicaron la dictadura chilena y argentina, los cuales consistían en arrojar a prisioneros sobre las playas o mares, aumentando el terror entre la inocente población. Es notable que ningún texto consultado llamara la atención sobre esta sugerente correlación.

ESCENA . Revista de las artes, 2021, Vol. 80, Núm. 2 (enero-junio), pp. 127-151 
pesar de la sugerente crítica, esta no tuvo lugar en Chile, no fue necesariamente pública ni recibió mayor reconocimiento artístico.

Por otra parte, la más reconocida de las obras del CADA, fue el grafiti de "NO +", escrito en infinidad de muros a lo largo y ancho de la capital chilena durante los años de 1983 y 1984. El Colectivo y otros artistas invitados de diferentes procedencias, colaboraron en la inscripción inicial, mientras que la sociedad civil, lenta y subrepticiamente, agregaron las consignas resultantes de "NO +" violencia, dictadura, represión, entre otras. Años después, esta misma se convertía en parte de la campaña del referéndum para acabar con la dictadura; movimiento que obtuvo la victoria ${ }^{15}$. De acuerdo con Robert Neustadt (2013), esta intervención del espacio público se convirtió en propiedad de la comunidad, logró el objetivo último de trascender, incluso, más allá del momento y lugar en que se inscribió, puesto que luego fue utilizado para denunciar otras opresiones en todo el mundo e, inclusive, ha sido reapropiada por grupos o manifestaciones neoconservadoras. Además, cabe señalar que, para octubre de 1984, la dictadura contraatacó, reforzando el estado de sitio, el silencio y aplicando más represión sobre los endebles medios de comunicación. Pinochet fortaleció los principios totalitarios: prohibiciones, arrestos, exilios, censuras y demás represiones a la libertad (Richard, 2004).

Por último, tras ese nuevo episodio de la dictadura revigorizada, en 1985 se publicó en las revistas Análisis, Cauce, Apsi y el periódico La Época, la fotografía titulada "Viuda". En esta ocasión, del CADA solo participaron Eltit y Rosenfeld, junto con otros artistas como Gonzalo Muñoz, Paz Errázuriz y la Agrupación de Mujeres por la Vida; el resto del Colectivo se encontraba fuera del país. Para esta ocasión, el tema de mayor peso se enfocó en el género, las mujeres, las personas vivas que habían tenido que sufrir las repercusiones directas de los crímenes y horrores de la dictadura, de los silencios imborrables y, sobre todo, de las ausencias. Precisamente, dado que se mostraba únicamente a una mujer, cuyo esposo había sido víctima de unos tiroteos en 1983 (Saul, 1985), el propósito era generar dudas, despertar conciencias y que las inquietudes se tornaran hacia aquellos maridos e hijos ausentes, desaparecidos. Pero, sobre todo, y en palabras de Walter Benjamin -otra víctima del fascismo- los muertos que no tienen túmulos (Sánchez, 2014, p. 33). La obra pretendía ser masificada y, con ello, se aseguraba su encubrimiento y la sociedad tenía la responsabilidad de reflexionar en torno a ella, de descifrarla.

${ }^{15}$ Según la lectura realizada por Neustadt de García Canclini, el grafiti es una intersección entre lo visual y lo literario, lo culto y lo popular (Neustadt, 2013, p. 67). 
Entre la crítica sociopolítica y la utopía artística:

Dossier

el Colectivo de Acciones de Arte (CADA), 1979-1985

\section{Entre lo efímero y lo trascendental: el impacto sociopolítico del CADA}

En torno al Colectivo surgen una serie de preguntas que se imbrican directamente con debates acerca del arte contemporáneo, su impacto social, así como la forma en que se ha escrito una variante de historia oficial o, textos panegíricos en torno al CADA. Para empezar, autores como Katunaric (2008), Sánchez (2014), Saul (1985) e, incluso, en algunos pasajes de Neustadt (2013) muestran que el CADA era una muestra excepcional de arte crítico y de protesta en el arte chileno. Una lectura apresurada parece sugerir que fueron la primera avanzada o los únicos exponentes de este tipo de arte. Una posición similar comparte Vega (2013), quien insiste en que este grupo chileno es un ejemplo prístino de resistencia y de fusión de la crítica artística y política (pp. 42-43).

Es oportuno señalar que, desde mediados del siglo XX, las acciones de arte ya eran conocidas en Chile, sobresaliendo artistas como Alejandro Jodorowsky en la década de 1960 (radicado en México) y muchos otros ${ }^{16}$; en las cuales era común la celebración del caos, la liberación sexual, la desnudez en público, así como imágenes grotescas que funcionaban como alternativas al status quo. Por su parte, Camnitzer señala que el caso chileno era un tanto particular, ya que no se buscaba una ruptura artística, sino que se esmeraban en concepciones populares y las iniciativas más sugerentes -como la poeta-pintora Vicuña- se limitaron al espacio privado (2009, p. 114). Mientras que, durante el fallido gobierno de Allende, habían destacado los murales de las Brigadas Ramona Parra, con un fuerte contenido político y de crítica social. Asimismo, se tiende a obviar que gran parte de las puestas en escena seguían las pautas o corrientes de otros artistas latinoamericanos y globales, máxime cuando se toma en consideración que el CADA seguía una línea postmoderna y deconstruccionista (Neustadt, 2013, p. 43).

De lo anterior, también se destaca que el Colectivo ha tratado de ser representado como arquetípico del arte de vanguardia chileno, aislado y de nuevo, excepcional (considerado como el primero o único). No obstante, obras como "Residuos americanos" y "Viuda" reducen ese excepcionalismo, ya que son obras que, en algunos escritos, son tratadas como no-canónicas, puesto que la primera se exhibió en una galería (convencional) y, en Estados Unidos, mientras que la segunda contó con la participación de otros artistas, reduciendo hasta cierto punto, el protagonismo o conducción total del CADA.

16 Tales como José Balmes, Eduardo Martínez Bonati, Alberto Pérez y Gracia Barrios; así como la influencia de las escuelas de arte de las universidades.

ESCENA . Revista de las artes, 2021, Vol. 80, Núm. 2 (enero-junio), pp. 127-151 
Pero, en lugar de destacar sus colaboraciones o conexiones con el resto del mundo, se describe con cierta insistencia que las muestras estaban "corrigiendo la vida con el arte" o que la ciudadanía estaba entendiendo el mensaje, la lucha por la democratización iba en aumento, etcétera ${ }^{17}$. Nelly Richard y Neustadt han enfatizado que, a pesar de las pretensiones del Colectivo en torno a un arte que despertaba el pensamiento, se alejaba de los convencionalismos y la vulgar publicidad. En la práctica, sobresalían el carácter utópico y los tonos de tipo mesiánico, predicante y militante o inclusive, un espíritu de secta (Richard, 1991, p. 109; Neustadt, 2013, p. 183).

Es importante señalar que Richard escribió ese balance años después de las sendas críticas que recibió tras su labor de curaduría en la Bienal de París (1982). En aquella ocasión seleccionó a un grupo de artistas, entre los que se contaba el CADA y figuras como Carlos Leppe, Carlos Altamirano, Eugenio Dittborn, entre otros. La muestra terminó siendo catalogada por algunos críticos y publicaciones especializadas, como "imitaciones obsoletas del arte de vanguardia", provincianas -dentro del marco internacional- e inclusive, artísticamente ingenuas (Macchiavello, 2014, p. 90). Asimismo, estas críticas incidieron en que el Colectivo fuera rechazado en la Bienal de Sídney (1984) y constituyeron parte de los factores que sepultaron al grupo. Paralelamente, se les acusó de ilegibles e imposibles de apreciar en otros contextos, así como obsoletos, ya que se consideraba que Chile estaba demasiado aislado de los circuitos artísticos y el contexto de la dictadura, no era suficiente excusa (Macchiavello, 2014, p. 106). Los cuestionamientos no se detuvieron y los artistas también fueron catalogados de autocomplacientes, nacionalistas y, más importante, la escena de avanzada se enfrascaba en presentarse como una especie de excepcionalidad, incomprendida ante los ojos colonialistas de Europa y, simultáneamente, negaba sus raíces en el propio arte de vanguardia chileno (Macchiavello, 2014, p. 97-98). Entonces, durante esos años, la recepción del Colectivo y otros afines no fue tan positiva, como algunos textos han pretendido.

En consecuencia, cabe preguntarse: ¿careció de valor artístico el CADA?, ¿resultaba frívolo?, ¿eran sus acciones efímeras y magnificadas solo por ensayos posteriores? La respuesta resulta, en general, negativa. Debe tomarse en cuenta que el grupo operó en medio del apagón cultural al que Chile estaba sometido, mientras que la supuesta frivolidad o el

${ }^{17}$ La misma Richard también agrega apologías de un tono más que llamativo que los "[artistas de la nueva escena]....se distinguen por su explosivo cuestionamiento de la institucionalidad del sistema artístico y literario dominante y de sus fraudes de sentido" (1991, p. 108).

ESCENA . Revista de las artes, 2021, Vol. 80, Núm. 2 (enero-junio), pp.127-151 
Entre la crítica sociopolítica y la utopía artística:

Dossier

el Colectivo de Acciones de Arte (CADA), 1979-1985

nivel de alcance social que alcanzó, estaba marcado precisamente por las dificultades de expresar un delicado mensaje político en circunstancias más que adversas. El tono ambiguo y hasta hermético, era necesario para asegurar la supervivencia del proyecto, aunque eso implicara que los acusaran de elitistas o que sus expresiones se tornaran banales. No obstante, y en ello también ha insistido Richard, dado la estrecha superposición entre arte y política, se llegaron a confundir la representación artística con la lucha política.

En palabras más sencillas, las acciones del CADA a veces lucen más cerca de protestas sofisticadas o ingeniosas críticas que sortean la represión, que como muestras correspondientes al arte contemporáneo. Vinculado a esto, eran acciones artísticas que exigen de contextualización, ya que la manta sobre el Museo o las bolsas de leche, no tendrían el mismo significado en otros momentos ni lugares. Inclusive, para muchos pobladores chilenos no capitalinos, el impacto semántico probablemente era menor o inexistente, ya que con la rampante censura es probable que se mantuvieran en buena medida al margen de estos eventos. Así, el CADA no recibió mayor atención en los principales medios de comunicación, uno de los objetivos máximos del régimen.

Aunque en defensa del grupo, cabe señalar, que sus obras no se trataban de objetos basura (ni mercancías burguesas especulativas) que encumbraran a unos elitistas autores, tampoco se concentraban en la creación de obras estrictamente novedosas. Por supuesto, la fugacidad caracterizaba al grueso de las muestras, pero la ambición, a veces desmedida del grupo, era tomar una idea y plasmarla, como lo señaló Heinich (2017, p. 348). Pero no cualquier idea, eran efímeras, porque la memoria se desvanece y, más allá de ello, se pretendía herir a una dictadura que se auto concebía como todopoderosa y ahí radicaba una de las ideas más fuertes del Colectivo. Aunque Macchiavello sitúa estas acciones de arte más cerca de la obsolescencia y las acusa de un exceso de autorreferentes políticos (2014, p. 111), la postura de García Canclini sería, en general, menos optimista, ya que el rechazo podía ser el resultado principal:

Lo mismo ocurre con las obras que pretenden obligar a la reacción militante: fracasan en su objetivo político tanto como en el estético, y otro tanto ocurre con aquellas que llevan fines pedagógicos y pretenden mostrar al espectador lo que no sabe (García Canclini, 2010, p. 227).

En el caso de CADA no fue un fracaso, sino que aportó herramientas para la resistencia. Así que sus resultados fueron exitosos hasta cierto punto, máxime cuando se toma 
en consideración que la Dictadura no logró apropiarse de estos movimientos ni resignificarlos a su favor. El problema, más bien, radicó en la forma en que se han comprendido/ interpretado estas victorias. Es indispensable tomar en consideración, que el Colectivo es un producto inseparable de su época, por tanto, aplicar sus estrategias y performances en otro momento es un anacronismo (Smith, 2011, p. 26-27) y muchos textos, precisamente, lo que quieren es despojarlo de su contexto, tal como lo hizo Katunaric (2008, p. 306).

Retomando el punto de la historia oficial, es factible y se apunta como una hipótesis, que la magnificación (¿o canonización?) que ha experimentado el CADA, se debe a su relevante papel dual de resistencia y expresión artística, sobre todo, en momentos trágicos de la historia chilena. Es más sensato elogiar a un grupo de jóvenes artistas que recordar la brutalidad de una dictadura de diecisiete años ${ }^{18}$. Aunque aquí es donde, precisamente, se podría estar construyendo el mito: al igual que ha ocurrido con otros artistas contemporáneos de todo el mundo, sus obras y escenificaciones, se pueden emplear como sustitutos edulcorados de la cruel realidad.

Se entiende el uso de la manta o de ropa desechada, pero ninguna emula, ni es una metáfora satisfactoria de los horrores de los campos de concentración, las torturas, los desaparecidos, las miles de personas olvidadas y arrojadas al vacío. Por eso, estas intervenciones o performance pueden lucir excesivamente efímeras y como meros cuestionamientos vainilla o vedados que no van más allá (Jiménez, 2010, p. 267). Incluso, se pueden confundir con válvulas de escape que no cambian el sistema establecido. Reconocer el valor del CADA, debe ir paralelo a la comprensión y rememoración de las víctimas, de las injusticias, que al final de cuenta, se les estaba tributando con cada acción de arte.

\section{Conclusiones}

Uno de los principales aspectos que se busca destacar es que el Colectivo de Acciones de Arte o CADA no era un caso insólito, no solo dentro de las fronteras chilenas, sino, en el grueso de Latinoamérica. No obstante, era un producto de la época y, más importante,

${ }^{18}$ EI CADA se escapa de las concepciones de artistas excéntricos y que destacan en las biografías e historias del arte: el exceso, la locura, el desenfreno, la melancolía (Heinich, 2003, p. 39); todos son elementos ajenos a esta propuesta en particular. En síntesis, el Colectivo escapaba a los estereotipos del arte y se acercaba más a los arquetipos de la lucha social, común en esas décadas o, ¿es así como han sido dibujados por distintos autores?

ESCENA . Revista de las artes, 2021, Vol. 80, Núm. 2 (enero-junio), pp.127-151 
Entre la crítica sociopolítica y la utopía artística:

Dossier

el Colectivo de Acciones de Arte (CADA), 1979-1985

de las excepcionales condiciones en que se encontraba Chile, en la cuales, el Colectivo no solo ejerció como parte de una lenta resurrección del arte, también, cumplió una función primaria en la reactivación del ejercicio ciudadano, aplacado por la dictadura. Por supuesto, esto lleva al debate entre un CADA más próximo a la protesta, que al arte mismo.

Dejando de lado estas objeciones, es importante recalcar que otros artistas y organizaciones afines no tuvieron que sortear con los condicionantes que se interpusieron al CADA. Aunque la dictadura ya había entrado en una etapa menos represiva, sin duda, la sombra de los horrores y torturas iniciales se extendió por todo el territorio chileno, lo que probablemente impidió o acalló con premura otros proyectos político-artísticos, incluso más agresivos o explícitos. De ello, la necesidad del Colectivo de recurrir a lo efímero y ambiguo, ya que eran requisitos fundamentales para salvaguardar su integridad física y medir las posibles respuestas del gobierno de Pinochet; era una peligrosa danza con una bestia presta a encolerizarse.

A esto se suma, como lo ha cuestionado Nelly Richard, que el CADA oscilaba entre su tono utópico-militante y un cierto halo de elitismo intelectual, puesto que confiaba en las habilidades artísticas del espectador medio, pero no abandonaba su esperanza en la realización última de la democracia; era reflexivo y también populista. Su ambiguo arte, era -según su propia concepción- terreno fértil para la constante reinterpretación. Esto no exime que, a veces, pudiera ser simplemente concebido como altanería de una vanguardia (o post vanguardia) de jóvenes artistas que estaban en sintonía con las corrientes del arte contemporáneo internacional y que, al final de cuentas, no eran sustitutos de una Academia e intelectualidad censurada, ni encubrían la apremiante necesidad por reactivar la vida política chilena. Máximo, cuando las agendas entre artistas y científicos sociales, pronto se bifurcarían, ya que, tras la salida de Pinochet, el arte volvería a sus sitios tradicionales y perdería sus conexiones políticas. La prioridad ahora residía en reconstruir y abandonar el autoritarismo. En la actualidad, no existe la misma necesidad (ni impacto) de intervenir edificios públicos o lanzar consignas desde el aire; los simbolismos ya no serán los mismos.

Por otra parte, rescatar la memoria del CADA, encumbrarlos, no es obra de una mera tergiversación o de autores encantados con su obra, podría situarse en la necesidad de dar luz sobre un periodo siniestro en la historia contemporánea chilena. La audacia y valor de un grupo de jóvenes que innegablemente se burló de la dictadura y de las anquilosadas instituciones que le servían -el museo, las fuerzas militares- son dignos de una rememoración alegre y hasta ejemplarizante para los millones de personas que sufren y caen

ESCENA . Revista de las artes, 2021, Vol. 80, Núm. 2 (enero-junio), pp. 127-151 
víctimas de regímenes autoritarios; los cuales en muchos momentos parecen invencibles. Repartir una bolsa de leche o rayar un muro, tal vez parecieran irrelevante o hasta insultante para algunos, pero cuando el Gran Hermano planea ejecutarte y en medio de la mayor desesperación, cualquier acto honesto, como lo es decir la verdad y recordar la memoria negada, puede convertirse en el primer paso para derrumbar a los poderes fácticos. Nunca se debe subestimar la capacidad de lucha social que un simple gesto o proclama artística puede desencadenar.

Asimismo, el CADA debe ser ubicado sin mitificaciones ni tergiversaciones en su justo sitio en la historia y a la vez, no se deben olvidar a las decenas de miles de personas que perdieron sus vidas ante esta desquiciada dictadura. Víctimas, cuya muerte jamás se podrá justificar y, como bien pretendía el Colectivo con su manejo del pasado reciente chileno, deben ser rememoradas; ya que el olvido, es el primer paso para convocar nuevos horrores y cabe recordar, que el ser humano tiende a elevar exponencialmente su nivel de brutalidad. Esperemos que el arte siga floreciendo en su apego a la crítica sociopolítica y que no tenga la necesidad de recordar, otra vez, la destrucción y horror que volvimos a desatar.

\section{Referencias}

Acha, J. (1994). Las culturas estéticas de América Latina. México: UNAM.

Agamben, G. (2011). ¿Qué es lo contemporáneo? En Desnudez. Barcelona, España: Anagrama.

Bourdieu, P. (2010). El sentido social del gusto. Elementos para una sociología de la cultura. Buenos Aires, Argentina: Siglo XXI.

Bruna, S. (1976). Chile: la legalidad vencida. México: Serie Popular Era.

Museo Nacional, Centro de Arte. Reina Sofía. (s.f.a). CADA (Colectivo de Acciones de Arte) (Raúl Zurita, Fernando Balcells, Diamela Eltit, Lotty Rosenfeld, Juan Castillo). Chile, 1979-1985. Recuperado de https://www.museoreinasofia.es/coleccion/autor/cada-colectivo-acciones-arte-raul-zurita-fernando-balcells-diamela-eltit-lotty-0

Museo Nacional, Centro de Arte. Reina Sofía. (s.f.b). Obra compuesta: Para no morir de hambre en el arte. Recuperado de https://www.museoreinasofia.es/buscar?bundle $=0$ bra\&compuesta $=6668 \&$ page $=1$ 
Entre la crítica sociopolítica y la utopía artística:

Dossier

el Colectivo de Acciones de Arte (CADA), 1979-1985

Hemispheric Institute. (s.f.). CADA (Colectivo de Acciones de Arte). Recuperado de http://hemisphericinstitute.org/hemi/es/modules/itemlist/category/100-cada

Camnitzer, L. (2009). Didáctica de liberación. Arte conceptualista en América Latina. Murcia, España: Cendeac.

Collier, S. \& Sater, W. (1999). Historia de Chile, 1808-1994. Madrid, España: Cambridge University Press.

Danto, A. (1997). Después del fin del arte. Buenos Aires, Argentina: Paidos.

Errazuriz, L. (2009). Dictadura militar en Chile. Antecedentes del golpe estético-cultural. Latin American Review, 44 (2),136-157.

Foxley, A. (22-28 de julio de 1981). Un "maná" artístico. Hoy, 45-46.

García Canclini, N. (2010). La sociedad sin relato. Antropología y estética de la inminencia. Madrid, España: Katz.

Heinich, N. (2003). La sociología del arte. Buenos Aires, Argentina: Nueva Visión.

Heinich, N. (2017). El paradigma del arte contemporáneo. Estructuras de una revolución artística. Madrid, España: Casimiro.

Hinkelammert, F. (2012). Lo indispensable es inútil. Hacia una espiritualidad de la liberación. San José: Editorial Arlekín.

Jiménez, M. (2010). La querella por el arte contemporáneo. Buenos Aires, Argentina: Amorrortu.

Katunaric, C. (2008). CADA: un ejemplo de la resistencia del poder cultural chileno bajo dictadura. Pandora: revue d'etudes hispaniques, 8, 297-307.

Lechner, N. (1987). La democratización en el contexto de una cultura postmoderna. En Norbert Lechner (comp.), Cultura política y democratización (253-262). Buenos Aires, Argentina: CLACSO,

Lucena Salmoral, M. (2008). Historia de Iberoamérica: Historia contemporánea (volumen III). Madrid, España: Cátedra.

ESCENA . Revista de las artes, 2021, Vol. 80, Núm. 2 (enero-junio), pp. 127-151 
Macchiavello, C. (2014). Vanguardia de exportación: la originalidad de la "Escena de Avanzada" y otros mitos chilenos. En Fernanda Carvajal, María José Delpiano y Carla Macchiavello (eds.), Ensayos sobre artes visuales. Prácticas y discursos de loso años '70 y '80 en Chile. Santiago, Chile: LOM

Neustadt, R. (2013). CADA día: la creación de un arte social (serie Cuadernos de análisis y debate culturales). Chile: Editorial Cuarto Propio.

Richard, N. (1991). El signo heterodoxo. Nueva Sociedad, 116, 102-111.

Richard, N. (2004). Arte y política desde 1960 en Chile. Revista de Crítica Cultural, 2930.

Sánchez Schwember, B. (2014). El CADA y su mirada a la historia de postgolpe, una interpretación posible desde Walter Benjamin. Revista Poiésis, 23, 25-36.

Saul, E. (1985). Balance de una acción de arte. Reconocer su propia cara. Cauce, 45(2).

Smith, T. (2011) ¿Qué es el arte contemporáneo? Buenos Aires, Argentina: Siglo XXI.

Soto, P. (2016). Creación y crítica artística en Chile durante la dictadura de Augusto Pinochet: la épica artística de la Avanzada. Interpretextos, 16, 215-240.

Taylor, D. \& Fuentes M. (editoras). (2011). Estudios avanzados de performance. México: Fondo de Cultura Económica, Instituto Hemisférico de Performance y Política, Tisch School of the Arts, New York University.

Vega, C. (2013). El Colectivo de Acciones de Arte y su resistencia artística contra la dictadura chilena (1979-1985). Revista Divergencia, 3, 37-48.

Zurita, R. (s.f.a). Colectivo de Acciones de Arte (CADA) [sitio web]. Recuperado de http://www.memoriachilena.gob.cl/602/w3-article-98248.html 